\title{
The median effective concentration of propofol with different doses of esketamine during gastrointestinal endoscopy in elderly patients:a randomized controlled trial
}

\author{
Hua Yang ${ }^{1}$, Qian Zhao ${ }^{1}$, Hai-yan Chen ${ }^{1}$, Wen Liu ${ }^{1}$, Tong Ding ${ }^{1}$, Bin Yang $^{1}$, and Jin-Chao \\ Song ${ }^{1}$ \\ ${ }^{1}$ Affiliation not available
}

May 28, 2021

\begin{abstract}
Abstract Background: Propofol may result in hypotension, bradycardia, and loss of protective reflexes, especially in elderly patients, while esketamine, a N-methyl-D-aspartate receptor antagonists, has analgesic, anaesthetic and sympathomimetic properties and is known to cause less cardiorespiratory depression. We hypothesized that esketamine may reduce the median effective concentration (EC50) of propofol and cause more stable haemodynamic responses during gastrointestinal endoscopy in elderly patients. Methods: Ninety elderly patients, aged 65-89 years, undergoing gastrointestinal endoscopy were randomly assigned into three groups: SK0.25 group $(0.25 \mathrm{mg} / \mathrm{kg}$ esketamine), SK0.5 group $(0.5 \mathrm{mg} / \mathrm{kg}$ esketamine) and saline control group. Anaesthesia was achieved by target-controlled infusion of propofol with an initial plasma concentration of $2.5 \mu \mathrm{g} / \mathrm{ml}$ with different bolus doses of esketamine during gastrointestinal endoscopy. The EC50 of propofol for gastrointestinal endoscopy was determined by using an up-and-down method of Dixon with an adjacent concentration gradient at $0.5 \mu \mathrm{g} / \mathrm{mL}$ to prohibit purposeful movements. Cardiovascular parameters were also measured and recorded. Results: Propofol EC50 and its $95 \%$ confidence interval for gastrointestinal endoscopy in elderly patients were $1.71(1.15-2.27) \mu \mathrm{g} / \mathrm{mL}$ in SK0.5 group, 2.45 (1.85$3.05) \mu \mathrm{g} / \mathrm{mL}$ in SK0.25 group and $3.69(2.59-4.78) \mu \mathrm{g} / \mathrm{mL}$ in control group respectively $(\mathrm{P}<0.05)$. The average percent change to baseline mean arterial pressure (MBP) was -19.7 (7.55), -15.2 (7.14) and -10.1 (6.73) with $\mathrm{P}$ j0.001, in the control group, the SK0.25 group and the SK0.5 group, respectively. Conclusions: Combination medication of propofol with esketamine reduced the propofol EC50 during gastrointestinal endoscopy in elderly patients and caused more stable haemodynamic responses compared with single administration of propofol.
\end{abstract}

The median effective concentration of propofol with different doses of esketamine during gastrointestinal endoscopy in elderly patients:a randomized controlled trial

Hua Yang, M.D. ${ }^{1, *}$, Qian Zhao, M.D. ${ }^{1, *}$, Hai-yan Chen, M.D. ${ }^{1, *}$, Wen Liu, M.D. ${ }^{1}$, Tong Ding, M.D. ${ }^{1}$, Bin Yang, M.D. ${ }^{2,}$ \#, Jin-Chao Song, M.D. ${ }^{1, \#}$

1 Department of Anesthesiology, Shidong Hospital of Shanghai, University of Shanghai for Science and Technology, Shanghai, China

2 Department of Anesthesiology, Chongqing University Cancer Hospital, Chongqing, China

\#Corresponding Author:

Jin-chao Song, Department of Anesthesiology, Shidong Hospital of Shanghai, University of Shanghai for Science and Technology, Shiguang Rd., No. 999, Shanghai, China. E-mail: sjch2013@163.com

Bin Yang, Department of Anesthesiology, Chongqing University Cancer Hospital, Hanyu Rd., No.181, Shapingba District, Chongqing, China. E-mail: yangbin4332@outlook. com 
*These authors contributed equally to this work.

Availability of data and material: applicable

Funding: The trial is supported by the Yangpu District Good-Doctor Program.

Conflict of interest statement: There are no commercial or financial interests involved in this work.

Ethics approval: The trail is approved by the Committee on Ethics of Biomedicine Research, Shidong Hospital.

Patient consent statement: Written consent was obtained from all patients.

permission to reproduce material from other sources: No material from other sources.

Trial registration: Chinese Clinical Trial Registry ChiCTR2100042252.

\begin{abstract}
Background: Propofol may result in hypotension, bradycardia, and loss of protective reflexes, especially in elderly patients, while esketamine, a N-methyl-D-aspartate receptor antagonists, has analgesic, anaesthetic and sympathomimetic properties and is known to cause less cardiorespiratory depression. We hypothesized that esketamine may reduce the median effective concentration $\left(\mathrm{EC}_{50}\right)$ of propofol and cause more stable haemodynamic responses during gastrointestinal endoscopy in elderly patients. Methods: Ninety elderly patients, aged 65-89 years, undergoing gastrointestinal endoscopy were randomly assigned into three groups: SK0.25 group ( $0.25 \mathrm{mg} / \mathrm{kg}$ esketamine), SK0.5 group (0.5 mg/kg esketamine) and saline control group. Anaesthesia was achieved by target-controlled infusion of propofol with an initial plasma concentration of $2.5 \mu \mathrm{g} / \mathrm{ml}$ with different bolus doses of esketamine during gastrointestinal endoscopy. The EC 50 of propofol for gastrointestinal endoscopy was determined by using an up-and-down method of Dixon with an adjacent concentration gradient at $0.5 \mu \mathrm{g} / \mathrm{mL}$ to prohibit purposeful movements. Cardiovascular parameters were also measured and recorded.Results: Propofol $\mathrm{EC}_{50}$ and its $95 \%$ confidence interval for gastrointestinal endoscopy in elderly patients were $1.71(1.15-2.27) \mu \mathrm{g} / \mathrm{mL}$ in SK0.5 group, 2.45 (1.85-3.05) $\mu \mathrm{g} / \mathrm{mL}$ in SK0.25 group and $3.69(2.59-4.78) \mu \mathrm{g} / \mathrm{mL}$ in control group respectively $(\mathrm{P}<0.05)$. The average percent change to baseline mean arterial pressure (MBP) was -19.7 (7.55), -15.2 (7.14) and -10.1 (6.73) with $\mathrm{P} j 0.001$, in the control group, the SK0.25 group and the SK0.5 group, respectively.Conclusions: Combination medication of propofol with esketamine reduced the propofol $\mathrm{EC}_{50}$ during gastrointestinal endoscopy in elderly patients and caused more stable haemodynamic responses compared with single administration of propofol.
\end{abstract}

\title{
Introduction
}

Gastrointestinal endoscopy is an essential screening and therapeutic tool for gastrointestinal diseases. It is important to perform endoscopic procedures under sedation for higher patient comfort and acceptance [1,2]. Propofol, a good hypnotic with rapid onset, rapid recovery, and minimal side effects, is the most widely used in anesthesia induction and maintenance during endoscopic procedures [3-7]. However, propofol may result in hypotension, bradycardia, respiratory depression, and loss of protective reflexes [8], especially in elderly patients. Adjuvants are usually needed in many cases because co-administration can improve anaesthetic efficacy and reduce the incidences of adverse events caused by a single drug [9].

Esketamine, a noncompetitive, N-methyl-D-aspartate receptor antagonists [10], has analgesic, anaesthetic and sympathomimetic properties and is known to cause less cardiorespiratory depression [11,12]. Therefore, it could be an ideal adjunct to propofol for endoscopic procedures $[12,13]$. However, very few studies have been reported the effectiveness and safety of esketamine adjunct to propofol sedation during endoscopic procedures in elderly patients.

We therefore designed this randomized, double-blinded and controlled study to assess the effectiveness and safety of esketamine as an adjunct to propofol target-controlled infusion (TCI) and determine the effect of different doses of esketamine on the median effective concentration $\left(\mathrm{EC}_{50}\right)$ of propofol for gastrointestinal endoscopy in elderly patients. 


\section{Methods}

\section{Study design and patients}

This randomized, double-blinded and controlled study was approved by the Committee on Ethics of Biomedicine Research, Shidong Hospital in Shanghai and was also registered in Chinese Clinical Trial Registry ChiCTR2100042252 prior to its start. A total of 90 ASA I-III elderly patients undergoing gastrointestinal endoscopy from November, 2020 to March, 2021, aged 65-89 years, were enrolled in this study and patients' consents were signed before the endoscopic procedures. In our gastrointestinal endoscopy center, as a routine, each patient undergoes both gastroscopy and colonoscopy under one anesthesia experience.

\section{Criteria for inclusion and exclusion}

Patients were included if they (1) were 65-89 years old; (2) were American Society Anesthesiologists physical status (ASA) I to III; (3) had body mass index (BMI) $19-27 \mathrm{~kg} / \mathrm{m}^{2}$.

Patients were excluded when they had (1) allergy to either esketamine or propofol; (2) alcohol abuse; (3) chronic use of sedative or analgesics; (4) neurological or pyschiatric disorders; (5) heart failure (ejection fraction $<40 \%$ ); (6) severe respiratory disease (vital capacity and/or forced expiratory volume <50\%); (7) end stage liver or renal diseases or (8) uncontrolled hypertension, blood pressure is over $180 / 120 \mathrm{mmHg}$.

\section{Preoperative preparations and anesthesia protocol}

The patients were computer-randomized into three groups, SK0.25 group (0.25 mg. $\mathrm{kg}^{-1}$ esketamine), SK0.5 group (0.5 mg. $\mathrm{kg}^{-1}$ esketamine) and saline control group (equivalent volume of normal saline). The patients, anesthesiologist, gastroenterologists and nurses in the recovery room were blinded to the grouping.

After an overnight fasting, the non-premedicated patients were brought to the endoscopy room, where a 20 -gauge intravenous cannula was established in the peripheral vein for Ringer Lactate solution infusion and drugs. Heart rate (HR), noninvasive blood pressure (BP), electrocardiogram (ECG) and peripheral oxygen saturation $\left(\mathrm{SpO}_{2}\right)$ were monitored continuously during endoscopic procedures (Philips HP Viridia 24/26 M1205A). Oxygen was administered at a rate of $3 \mathrm{~L} / \mathrm{min}$ by nasal catheter during the study.

After preoxygenation, propofol (AstraZeneca Company, Italy) was administered by a computer-controlled infusion TCI (Graseby 3500 TCI Syringe Pump, SIMS Graseby Ltd., Herts, England) using the Marsh pharmacokinetic parameters at an initial plasma target concentration of $2.5 \mu \mathrm{g} / \mathrm{mL}$ in three groups. We started the first dose of propofol at $2.5 \mu \mathrm{g} / \mathrm{mL}$ based on our pre-test. Once the target concentration of propofol achieved, esketamine was injected immediately. All esketamine solutions were diluted into $10 \mathrm{ml}$ and prepared by an anesthesiologist nurse who was no longer involved in the follow-up. Patients were administered with different doses of esketamine: $0.25 \mathrm{mg} / \mathrm{kg}$ esketamine (SK0.25 group), $0.5 \mathrm{mg} / \mathrm{kg}$ esketamine (SK0.5 group) and blank saline solution (Control group). In our endoscopy center, as a rule, the patients underwent gastroscopy first followed by colonoscopy. Qualified and experienced gastroenterologists started gastroscopy 3 min after esketamine injection and propofol TCI pump was stopped just before the end of the colonoscopy. Coughing, retch, and purposeful movement of the head or limbs during endoscopy are defined as "responsive". If the patient presented "responsive", propofol 2-3 $\mathrm{mL}$ was given as a rescue medication immediately, and the target plasma concentration of propofol for the subsequent patient would be increased by $0.5 \mu \mathrm{g} / \mathrm{mL}$. If coughing, or retch, or purposeful movements did not occur, which defined as "non-responsive", the subsequent target plasma concentration of propofol was decreased by $0.5 \mu \mathrm{g} / \mathrm{mL}$. This method was called up-and-down method of Dixon, described as early in 1965 [14].

Emergency equipment was available throughout the procedure. A bolus of 6-10 mg ephedrine was given once mean arterial pressure (MBP) decrease by $30 \%$ over the baseline value, and $0.25 \mathrm{mg}$ atropine was injected once heart rate (HR) fell below $50 \mathrm{bpm}$. Appropriate nitroglycerin was injected once MBP rose above $120 \mathrm{mmHg}$. If spontaneous ventilation was insufficient $\left(\mathrm{SpO}_{2}<90 \%\right)$, the anesthesiologist performed an unarmed airway opening and an artificial ventilation support as necessary.

\section{Measurements}


Baseline values of MBP and HR were defined as the lowest of the three measurements during 3 min interval just before TCI propofol. MBP and HR were measured and recorded at the designated time points and at a 3-min interval duration of endoscopic procedure. The designated time points: $\mathrm{T}_{0}=$ baseline values; $\mathrm{T}_{1}=$ the target concentration achieved after TCI propofol; $\mathrm{T}_{2}=3 \mathrm{~min}$ after esketamine injection; $\mathrm{T}_{3}=$ at scope intubation and $\mathrm{T}_{4-\mathrm{x}}=$ by 3 -min intervals during the procedure.

Perioperative anaesthesia related adverse events, such as bradycardia, hypotension, frequency of respiratory depression, nystagmus, mental symptoms, and postoperative nausea and vomiting (PONV) were also recorded. TCI propofol was maintained till the removal of the colonoscopy. Recovery time was defined as the time from discontinuing propofol to Observer's Assessment of Alertness/Sedation scale (OAA/S) $=5$ (responds readily to name spoken in normal tone). The endoscopic time were also recorded.

The patient's satisfaction with the procedure was assessed $45 \mathrm{~min}$ after endoscopic procedure as: 4, no discomfort; 3 , slightly uncomfortable; 2 , extremely uncomfortable; 1 , unacceptable. The gastroenterologist's satisfaction $(4=$ excellent, $3=$ good, $2=$ fair, $1=$ poor $)$ was assessed immediately after endoscopic procedure [15].

The primary endpoint was the median effective concentration $\left(\mathrm{ED}_{50}\right)$ of propofol with different doses of esketamine during gastrointestinal endoscopy in elderly patients. The secondary endpoint was to compare the change of haemodynamics among three groups: the average percent change to baseline in MBP and HR. We defined that percent change at the designated time points $=\left(\mathrm{MBP}_{\mathrm{T} 1-\mathrm{x}}-\mathrm{MBP}_{\mathrm{T} 0}\right) / \mathrm{MBP}_{\mathrm{T} 0} * 100$.

\section{Statistical analysis}

It was reported that anesthesia researches using the up-and-down methodology typically need 20-40 patients per group $[9,16,17]$. We have also considered a dropout rate of $10 \%$. Therefore, the estimated sample size will be 30 patients per group, and a total of 90 patients will be randomized.

Data were expressed as mean (standard deviation, SD) for continuous variables, median (Min, Max) for continuous variables with skewed distribution, or number (n) for categorical variables. First, all data are tested for normality by shapiro.test. For data that does not conform to the normal distribution, we use the Kruskal-Wallis rank sum test to check the differences between groups; for the data whose variance conforms to the normal distribution, we use the Bartlett test of homogeneity of variances to test whether the variances are homogeneous. Subsequently, we used ANOVA's Tukey method or Kramer Nemenyi test to test the differences between groups, as appropriate. The modified Dixon's up-and-down method was used for determining the $\mathrm{ED}_{50}$ of propofol with different doses of esketamine. We use Dixon method to test either the minimum or maximum value is an outlier. Using log-logistic dose-response model test was used to test the differences of $\mathrm{EC}_{50}$ between groups. We define $P$ value $<0.05$ as a significant difference between groups.

\section{Results:}

Fig.1 showed the study flow diagram. There was no statistical significance between characteristics of patients such as age, gender, BMI, or preoperative laboratory values (Table 1).

Propofol $\mathrm{EC}_{50}$ and its $95 \%$ confidence interval for gastrointestinal endoscopy in elderly patients were 1.71 $(1.15-2.27) \mu \mathrm{g} / \mathrm{mL}$ in SK0.5 group, $2.45(1.85-3.05) \mu \mathrm{g} / \mathrm{mL}$ in SK0.25 group and $3.69(2.59-4.78) \mu \mathrm{g} / \mathrm{mL}$ in control group respectively $\left(\mathrm{P}<0.05\right.$ ) (Table 2). $\mathrm{EC}_{50}$ of propofol in SK0.5 group and SK0.25 group was statistically significantly decreased compared with control group $(\mathrm{P}<0.05)$. Furthermore, there was statistically significant difference between SK0.5 group and SK0.25 group $(\mathrm{P}<0.05)$. The propofol TCI concentrations for consecutive patients and their responses to the gastrointestinal endoscopy are shown in Fig.2-4.

The average percent change to baseline MBP was -19.7 (7.55), -15.2 (7.14) and -10.1 (6.73) with $P$ ¡0.001, and average percent change to baseline HR was $-7.30(8.39),-5.41(9.68)$ and $-3.75(7.30)$ with $P=0.275$ in the control group, the SK0.25 group and the SK0.5 group, respectively (Table 3). MBP values in the SK0.25 group and the SK0.5 group decreased significantly less than those in the control group $(P$ i0.05). Figure 5,6 
shows the time course of percent change to baseline in MBP and HR. Recovery time in the control group was significantly longer than those in the SK0.25 group and the SK0.5 group $(P ; 0.001)$. There was no statistical significance between groups for patient satisfaction and gastroenterologist satisfaction $(P>0.05)$ (Table 3$)$.

The study was completed without any significant clinical complication. Major complications included hypotension or/and bradycardia (3 patients in control group), respiratory depression (1 patient in control group), PONV (1 patient in control group), and eye tremor (1 patient each for the SK0.25 group and the SK0.5 group). There was no psychotomimetic effects in our study.

\section{Discussion}

The primary endpoint of this study was to determine the median effective concentration of propofol with different doses of esketamine during gastrointestinal endoscopy in elderly patients. We found a significant decrease in propofol $\mathrm{EC}_{50}$ when co-administration with $0.5 \mathrm{mg} / \mathrm{kg}$ esketamine or $0.25 \mathrm{mg} / \mathrm{kg}$ esketamine. The secondary endpoint was to compare the change of haemodynamics among three groups. Our results show that the co-administration of esketamine and propofol caused more stable haemodynamic responses compared with single administration of propofol in elderly patients.

In this study, we used the modified Dixon's up-and-down methodology to determine the median effective concentration of propofol with different doses of esketamine, because the Dixon's up-and-down method has a long history $[18,19]$ and is often used in anesthesia research [16]. The advantage of the sequential method is that it can make full use of the data provided by fewer cases, and get results quickly and accurately. To adopt the sequential method, two conditions must be met: the dosage of the drug should be easy to change, and the negative or positive result can be quickly revealed. Both of propofol and esketamine meet the above two conditions, so we can think that our sequential research method is feasible.

Various types of analgesic and sedative techniques have been used during gastrointestinal endoscopy. The propofol, a good hypnotic with rapid onset, short duration of action, and minimal side effects, is one of the most commonly used intravenous anesthetics during endoscopic procedure [5,7,20,21]. However, it was reported in a guideline of anesthesia and sedation in GI endoscopy that transient hypoxia occurs in $3 \%$ to $7 \%$ of cases using propofol sedation and that transient hypotension occurs in $4 \%$ to $7 \%$ of cases [22]. It is well known that propofol may cause shows dose-dependent hemodynamic instability, such as bradycardia and hypotension, during induction or bolus administration [23]. The hemodynamic instability is due to dose-dependent reduced systemic vascular resistance and myocardial contractility [24-26] especially in elderly patients. Many studies also demonstrated that the requirements of propofol are reduced in elderly individuals $[27,28]$ because of the age-related changes in pharmacodynamics, pharmacokinetics or both [29].

Some studies are exploring the medication strategy of propofol for endoscopic procedure, such as combination medication to reduce the dosage of propofol requirement [9,30-32]. A randomized, double-blinded and controlled trial for elderly patients subjected to colonoscopy showed that $\mathrm{EC}_{50}$ of propofol was reduced when combined with $1 \mu \mathrm{g} / \mathrm{kg}$ fentanyl and there was no significant difference in adverse events but prolonged awake and discharge time [9]. Mortero et al.[30] demonstrate that the combination of propofol with small-dose ketamine reduced hypoventilation caused by propofol, induced positive mood effects, and produced earlier recovery of perception compared with propofol alone during monitored anesthesia for surgical interventions. Recently, Susanne Eberl et al. [32] found that the combination of esketamine with propofol for sedation in patients undergoing ERCP is superior to a combination of propofol with an opioid.

Esketamine, a N-methyl-D-aspartate receptor antagonist, has analgesic, anaesthetic and sympathomimetic properties. It is reported that esketamine cause less respiratory or cardiovascular depression than other sedatives due to an increase in sympathetic tone[12,32]. Jonkman $\mathrm{K}$ et al. found that esketamine could counter opioid-induced respiratory depression [11]. It is also reported that esketamine nasal spray could cause transient and asymptomatic blood pressure elevations [33]. Therefore, there has been growing interest in the use of esketamine as an ideal adjunct to propofol for procedural sedation and analgesia [12,34]. It was reported that the use of a combination of propofol and esketamine for procedural analgesia and sedation during MR-guided HIFU treatments of uterine fibroids is feasible and safe, with a short recovery time and 
a low risk of major adverse events [34]. Recently, Eberl, S. et al. demonstrated low-dose esketamine reduces the requirement of propofol for sedation during ERCP in ASA I-II patients without affecting recovery time, side effects, cardiovascular or respiratory adverse events and satisfaction of endoscopists and patients, when compared with alfentanil [12].

In this study, we demonstrated that combination medication of propofol with esketamine reduced the propofol $\mathrm{EC}_{50}$ during gastrointestinal endoscopy in elderly patients and caused more stable haemodynamic responses. Due to the decrease in the dose of propofol, the dose-dependent depression of propofol on the circulation was alleviated. Furthermore, the sympathomimetic properties of esketamine may, at least partially, counter propofol-induced haemodynamic depression.

There was a limitation in our study. When hypotension caused by excessive sedation occurs, we use vasoactive drugs to increase blood pressure without reducing the propofol infusion rate, which may lead to excessive sedation in some patients. A Bispectral Index or entropy monitoring should be considered during endoscopic procedure in our next step.

\section{Conclusions}

Combination medication of propofol with esketamine reduced the propofol $\mathrm{EC}_{50}$ during gastrointestinal endoscopy in elderly patients and caused more stable haemodynamic responses with the shorter recovery time and the same satisfaction of endoscopists and patients, when compared with single administration of propofol.

\section{Acknowledgements}

The authors thank Wen-hui Mo, MD, PhD, Jian-qing Chen MD, PhD and Professor Xuan-fu Xu (Endoscopy center, Shidong Hospital of Shanghai) for some suggestions. The authors are grateful for the financial supports from the Yangpu District Good-Doctor Program.

\section{References:}

1. Ferreira AO, Cravo M. Sedation in gastrointestinal endoscopy: Where are we at in 2014? World J Gastrointest Endosc 2015; 7: 102-9

2. Moon SH. Sedation regimens for gastrointestinal endoscopy. Clin Endosc 2014; 47: 135-40

3. Fanti L, Gemma M, Agostoni M, et al. Target Controlled Infusion for non-anaesthesiologist propofol sedation during gastrointestinal endoscopy: The first double blind randomized controlled trial. Dig Liver Dis 2015; 47: 566-71

4. Song JC, Lu ZJ, Jiao YF, et al. Etomidate Anesthesia during ERCP Caused More Stable Haemodynamic Responses Compared with Propofol: A Randomized Clinical Trial. Int J Med Sci 2015; 12: $559-65$

5. Angsuwatcharakon P, Rerknimitr R, Ridtitid W, et al. Cocktail sedation containing propofol versus conventional sedation for ERCP: a prospective, randomized controlled study. BMC Anesthesiol 2012; 12: 20

6. Jung M, Hofmann C, Kiesslich R, et al. Improved sedation in diagnostic and therapeutic ERCP: propofol is an alternative to midazolam. Endoscopy 2000; 32: 233-8

7. Kongkam P, Rerknimitr R, Punyathavorn S, et al. Propofol infusion versus intermittent meperidine and midazolam injection for conscious sedation in ERCP. J Gastrointestin Liver Dis 2008; 17: 291-7

8. Faigel DO, Baron TH, Goldstein JL, et al. Guidelines for the use of deep sedation and anesthesia for GI endoscopy. Gastrointest Endosc 2002; Nov;56(5):613-7

9. Li S, Yu F, Zhu H, et al. The median effective concentration (EC50) of propofol with different doses of fentanyl during colonoscopy in elderly patients. BMC Anesthesiol 2016; 16: 24

10. Saad Z, Hibar D, Fedgchin M, et al. Effects of Mu-Opiate Receptor Gene Polymorphism rs1799971 (A118G) on the Antidepressant and Dissociation Responses in Esketamine Nasal Spray Clinical Trials. Int J Neuropsychopharmacol 2020; 23: 549-558 
11. Jonkman K, van Rijnsoever E, Olofsen E, et al. Esketamine counters opioid-induced respiratory depression. Br J Anaesth 2018; 120: 1117-1127

12. Eberl S, Koers L, van Hooft J, et al. The effectiveness of a low-dose esketamine versus an alfentanil adjunct to propofol sedation during endoscopic retrograde cholangiopancreatography: A randomised controlled multicentre trial. Eur J Anaesthesiol 2020; 37: 394-401

13. Wang J, Huang J, Yang S, et al. Pharmacokinetics and Safety of Esketamine in Chinese Patients Undergoing Painless Gastroscopy in Comparison with Ketamine: A Randomized, Open-Label Clinical Study. Drug Des Devel Ther 2019; 13: 4135-4144

14. Hanley C, Zerbolio DJ. Developmental changes in five illusions measured by the up-and-down method. Child Dev 1965; 36: 437-52

15. Manolaraki MM, Theodoropoulou A, Stroumpos C, et al. Remifentanil compared with midazolam and pethidine sedation during colonoscopy: a prospective, randomized study. Dig Dis Sci 2008; 53: 34-4

16. Pace NL, Stylianou MP. Advances in and limitations of up-and-down methodology: a précis of clinical use, study design, and dose estimation in anesthesia research. Anesthesiology 2007; 107: 144-52

17. Fu F, Chen X, Feng Y, et al. Propofol EC50 for inducing loss of consciousness is lower in the luteal phase of the menstrual cycle. Br J Anaesth 2014; 112: 506-13

18. Scheller MS, Saidman LJ, Partridge BL. MAC of sevoflurane in humans and the New Zealand white rabbit. Can J Anaesth 1988; 35: 153-6

19. Rampil IJ, Lockhart SH, Zwass MS, et al. Clinical characteristics of desflurane in surgical patients: minimum alveolar concentration. Anesthesiology 1991; 74: 429-33

20. Levitt C, Wei H. Supraglotic pulsatile jet oxygenation and ventilation during deep propofol sedation for upper gastrointestinal endoscopy in a morbidly obese patient. J Clin Anesth 2014; 26: 157-9

21. Wehrmann T, Kokabpick S, Lembcke B, et al. Efficacy and safety of intravenous propofol sedation during routine ERCP: a prospective, controlled study. Gastrointest Endosc 1999; 49: 677-83

22. Standards of Practice Committee of the American Society for Gastrointestinal Endoscopy, Lichtenstein DR, Jagannath S, et al. Sedation and anesthesia in GI endoscopy. Gastrointest Endosc 2008; 68: 815-26

23. Claeys MA, Gepts E, Camu F. Haemodynamic changes during anaesthesia induced and maintained with propofol. Br J Anaesth 1988; 60: 3-9

24. Gragasin FS, Davidge ST. The effects of propofol on vascular function in mesenteric arteries of the aging rat. Am J Physiol Heart Circ Physiol 2009; 297: H466-74

25. Memtsoudis SG, The AH, Heerdt PM. Autonomic mechanisms in the age-related hypotensive effect of propofol. Anesth Analg 2005; 100: 111-5

26. John AD, Sieber FE. Age associated issues: geriatrics. Anesthesiol Clin North Am 2004; 22: 45-58

27. You AH, Kim JY, Kim DH, et al. Effect of remifentanil and midazolam on ED95 of propofol for loss of consciousness in elderly patients: A randomized, clinical trial. Medicine (Baltimore) 2019; 98: e15132

28. Dahaba AA, Zhong T, Lu HS, et al. Geographic differences in the target-controlled infusion estimated concentration of propofol: bispectral index response curves. Can J Anaesth 2011; 58: 364-70

29. Irwin MG, Hui TW, Milne SE, et al. Propofol effective concentration 50 and its relationship to bispectral index. Anaesthesia 2002; 57: 242-8

30. Mortero RF, Clark LD, Tolan MM, et al. The effects of small-dose ketamine on propofol sedation: respiration, postoperative mood, perception, cognition, and pain. Anesth Analg 2001; 92: 1465-9

31. Vallejo MC, Romeo RC, Davis DJ, et al. Propofol-ketamine versus propofol-fentanyl for outpatient laparoscopy: comparison of postoperative nausea, emesis, analgesia, and recovery. J Clin Anesth 2002; 14: 426-31

32. Eberl S, Koers L, van Hooft JE, et al. Sedation with propofol during ERCP: is the combination with esketamine more effective and safer than with alfentanil? Study protocol for a randomized controlled trial. Trials 2017; 18: 472

33. Doherty T, Wajs E, Melkote R, et al. Cardiac Safety of Esketamine Nasal Spray in Treatment-Resistant Depression: Results from the Clinical Development Program. CNS Drugs 2020; 34: 299-310

34. Vaessen HHB, Knuttel FM, van Breugel JMM, et al. Moderate-to-deep sedation technique, using propofol and ketamine, allowing synchronised breathing for magnetic resonance high-intensity focused 
ultrasound (MR-HIFU) treatment for uterine fibroids: a pilot study. J Ther Ultrasound 2017; 5: 8

Table 1 Characteristics of participants.

\begin{tabular}{|c|c|c|c|c|c|c|}
\hline & $\begin{array}{l}\text { Control } \\
(\mathrm{N}=30)\end{array}$ & $\begin{array}{l}\text { Control } \\
(\mathbf{N}=30)\end{array}$ & $\begin{array}{l}\text { Group } \\
\text { SK0.25 } \\
(\mathrm{N}=30)\end{array}$ & $\begin{array}{l}\text { Group } \\
\text { SK0.5 } \\
(\mathrm{N}=30)\end{array}$ & $\begin{array}{l}\text { statistic } \\
\text { method }\end{array}$ & $\mathbf{P}$ \\
\hline $\begin{array}{l}\text { Gender } \\
(\mathrm{M} / \mathrm{F})\end{array}$ & $10 / 20$ & $10 / 20$ & $10 / 20$ & $11 / 19$ & $\begin{array}{l}\text { Kruskal- } \\
\text { Wallis rank } \\
\text { sum test }\end{array}$ & 0.95 \\
\hline Age (yrs) & $\begin{array}{l}70.0[65.0, \\
88.0]\end{array}$ & $\begin{array}{l}70.0[65.0, \\
89.0]\end{array}$ & $\begin{array}{l}70.0[65.0, \\
89.0]\end{array}$ & $\begin{array}{l}69.5[65.0, \\
88.0]\end{array}$ & $\begin{array}{l}\text { Kruskal- } \\
\text { Wallis rank } \\
\text { sum test }\end{array}$ & 0.991 \\
\hline $\begin{array}{l}\text { BMI } \\
\left(\mathrm{kg} / \mathrm{m}^{2}\right)\end{array}$ & $24.2(2.25)$ & $23.8(2.73)$ & $23.8(2.73)$ & $24.8(2.45)$ & anova & 0.321 \\
\hline $\begin{array}{l}\text { ТВ } \Lambda \\
(\mu \mu \sigma \lambda / \Lambda)\end{array}$ & $\begin{array}{l}14.3[7.90, \\
24.8]\end{array}$ & $\begin{array}{l}12.1[9.40, \\
27.0]\end{array}$ & $\begin{array}{l}12.1[9.40, \\
27.0]\end{array}$ & $\begin{array}{l}14.2[9.30 \\
28.8]\end{array}$ & $\begin{array}{l}\text { Kruskal- } \\
\text { Wallis rank } \\
\text { sum test }\end{array}$ & 0.578 \\
\hline $\begin{array}{l}\text { Albumin } \\
(\mathrm{g} / \mathrm{L})\end{array}$ & $\begin{array}{l}43.2[35.7, \\
50.7]\end{array}$ & $\begin{array}{l}41.1[35.0, \\
47.3]\end{array}$ & $\begin{array}{l}41.1[35.0, \\
47.3]\end{array}$ & $\begin{array}{l}44.1[35.5, \\
47.9]\end{array}$ & $\begin{array}{l}\text { Kruskal- } \\
\text { Wallis rank } \\
\text { sum test }\end{array}$ & 0.306 \\
\hline $\begin{array}{l}\text { ALT } \\
(\mathbf{U} / \mathbf{L})\end{array}$ & $\begin{array}{l}18.0[10.0, \\
75.0]\end{array}$ & $\begin{array}{l}18.0[10.0, \\
40.0]\end{array}$ & $\begin{array}{l}18.0[10.0, \\
40.0]\end{array}$ & $\begin{array}{l}18.5[10.0, \\
52.0]\end{array}$ & $\begin{array}{l}\text { Kruskal- } \\
\text { Wallis rank } \\
\text { sum test }\end{array}$ & 0.988 \\
\hline $\begin{array}{l}\mathbf{A S T} \\
(\mathbf{U} / \mathbf{L})\end{array}$ & $\begin{array}{l}22.0[17.0, \\
76.3]\end{array}$ & $\begin{array}{l}24.0[16.0, \\
39.0]\end{array}$ & $\begin{array}{l}24.0[16.0, \\
39.0]\end{array}$ & $\begin{array}{l}21.0[13.0, \\
57.0]\end{array}$ & $\begin{array}{l}\text { Kruskal- } \\
\text { Wallis rank } \\
\text { sum test }\end{array}$ & 0.583 \\
\hline $\begin{array}{l}\text { SCR } \\
(\mathrm{mmol} / \mathrm{L})\end{array}$ & $\begin{array}{l}60.5[6.86, \\
291]\end{array}$ & $\begin{array}{l}61.2[45.0 \\
109]\end{array}$ & $\begin{array}{l}61.2[45.0, \\
109]\end{array}$ & $\begin{array}{l}59.4[38.5, \\
110]\end{array}$ & $\begin{array}{l}\text { Kruskal- } \\
\text { Wallis rank } \\
\text { sum test }\end{array}$ & 0.851 \\
\hline $\begin{array}{l}\text { BUN } \\
(\mathrm{mmol} / \mathrm{L})\end{array}$ & $4.71(1.55)$ & $5.17(1.63)$ & $5.17(1.63)$ & $5.29(1.64)$ & anova & 0.429 \\
\hline INR & $\begin{array}{l}0.906 \\
(0.0705)\end{array}$ & $\begin{array}{l}0.943 \\
(0.0586)\end{array}$ & $\begin{array}{l}0.943 \\
(0.0586)\end{array}$ & $\begin{array}{l}0.906 \\
(0.0541)\end{array}$ & anova & 0.098 \\
\hline
\end{tabular}

Data are Mean (SD), Median [Min, Max] or number.

Table 2. Propofol $\mathrm{EC}_{50}$ and its $95 \%$ confidence interval

Control

$(\mathrm{N}=30)$

\section{Group SK0.25}

$(\mathrm{N}=30)$

\section{Group SK0.5}

$(\mathrm{N}=30)$

Пролочо入 E" ${ }_{50}(\mu \gamma / \mu \Lambda)$

3.69 
Using log-logistic dose-response model test: ${ }^{*}$ Compared with Control, $P=0.0086$; ${ }^{* *}$ Compared with Control, $P=1.157 \times 10^{-5}$; \# Compared with Group SK0.25, $P=0.0284$.

Table 3 Procedure time, satisfaction, hemodynamics and recovery time $(\mathrm{n}=30$ in each)

\begin{tabular}{|c|c|c|c|c|c|}
\hline & $\begin{array}{l}\text { Control } \\
(\mathrm{N}=30)\end{array}$ & $\begin{array}{l}\text { Group SK0.25 } \\
(\mathrm{N}=30)\end{array}$ & $\begin{array}{l}\text { Group SK0.5 } \\
(\mathrm{N}=30)\end{array}$ & $\begin{array}{l}\text { statistic } \\
\text { method }\end{array}$ & $\mathrm{P}$ \\
\hline $\begin{array}{l}\text { Procedure } \\
\text { time (min) }\end{array}$ & $21.0[12.0,30.0]$ & $18.0[15.0,30.0]$ & $21.0[16.0,35.0]$ & $\begin{array}{l}\text { Kruskal-Wallis } \\
\text { rank sum test }\end{array}$ & 0.351 \\
\hline $\begin{array}{l}\text { Patient } \\
\text { satisfaction }\end{array}$ & $4[3,4]$ & $4[3,4]$ & $4[3,4]$ & $\begin{array}{l}\text { Kruskal-Wallis } \\
\text { rank sum test }\end{array}$ & 0.814 \\
\hline $\begin{array}{l}\text { Gastroenterolog } \\
\text { satisfaction }\end{array}$ & ist $[3,4]$ & $4[3,4]$ & $4[3,4]$ & $\begin{array}{l}\text { Kruskal-Wallis } \\
\text { rank sum test }\end{array}$ & 1 \\
\hline MBP (\%) & $-19.7(7.55)$ & $-15.2(7.14)^{*}$ & $-10.1(6.73)^{*}$ & anova & $6.63 \times 10^{-6}$ \\
\hline HR (\%) & $-7.30(8.39)$ & $-5.41(9.68)$ & $-3.75(7.30)$ & anova & 0.275 \\
\hline $\begin{array}{l}\text { Recovery time } \\
\text { (s) }\end{array}$ & $620[420,900]$ & $470[320,900]^{* *}$ & $420[300,720]^{* *}$ & $\begin{array}{l}\text { Kruskal-Wallis } \\
\text { rank sum test }\end{array}$ & $3.03 \times 10^{-6}$ \\
\hline
\end{tabular}

Data are Mean (SD) or Median [Min, Max]; ${ }^{*}$ Compared with Control using Tukey test, $p<0.05$;* Compared with Control using Tukey and Kramer Nemenyi test, $p<0.05$.

Awake time to OAA/S 5 (s)

Figure 1. Study flow diagram.

Figure 2. Consecutive target propofol concentrations during gastrointestinal endoscopy for $\mathrm{EC}_{50}$ determination in control group. The red dot represents "non-responsive"; and the blue triangle represents "responsive". The horizontal line represents the $\mathrm{ED}_{50}$. Propofol EC50 and its 95\% confidence interval were 3.69 (2.59-4.78) $\mu \mathrm{g} / \mathrm{mL}$.

Figure 3. Consecutive target propofol concentrations during gastrointestinal endoscopy for $\mathrm{EC}_{50}$ determination in SK0.25 group. The red dot represents "non-responsive"; and the blue triangle represents "responsive".

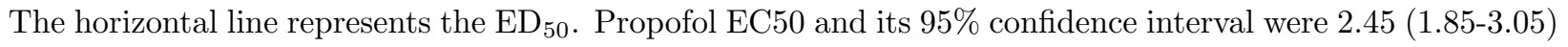
$\mu \mathrm{g} / \mathrm{mL}$.

Figure 4. Consecutive target propofol concentrations during gastrointestinal endoscopy for $\mathrm{EC}_{50}$ determination in SK0.5 group. The red dot represents "non-responsive"; and the blue triangle represents "responsive". The horizontal line represents the $\mathrm{ED}_{50}$. Propofol EC50 and its $95 \%$ confidence interval were 1.71 (1.15-2.27) $\mu \mathrm{g} / \mathrm{mL}$.

Figure 5. The time course of percent change to baseline in mean arterial pressure. $\mathrm{T}_{0}=$ baseline values; $\mathrm{T}_{1}=$ the target concentration achieved after TCI propofol; $\mathrm{T}_{2}=3 \mathrm{~min}$ after esketamine injection; $\mathrm{T}_{3}=$ at scope intubation and $\mathrm{T}_{4-\mathrm{x}}=$ by 3 -min intervals during the procedure.

Figure 6 . The time course of percent change to baseline in heart rate. $T_{0}=$ baseline values; $T_{1}=$ the target 
concentration achieved after TCI propofol; $\mathrm{T}_{2}=3$ min after esketamine injection; $\mathrm{T}_{3}=$ at scope intubation and $\mathrm{T}_{4-\mathrm{x}}=$ by 3 -min intervals during the procedure.
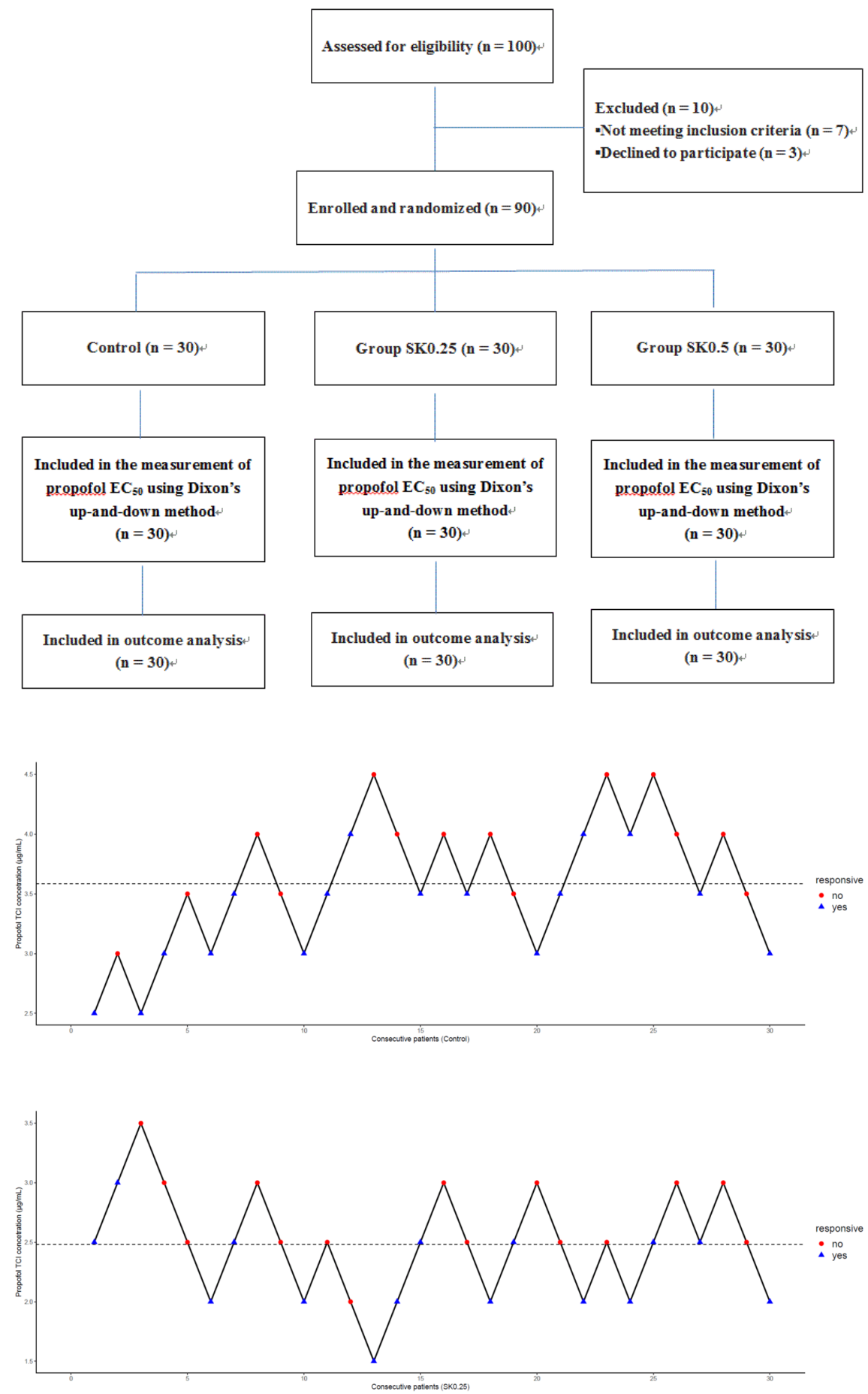

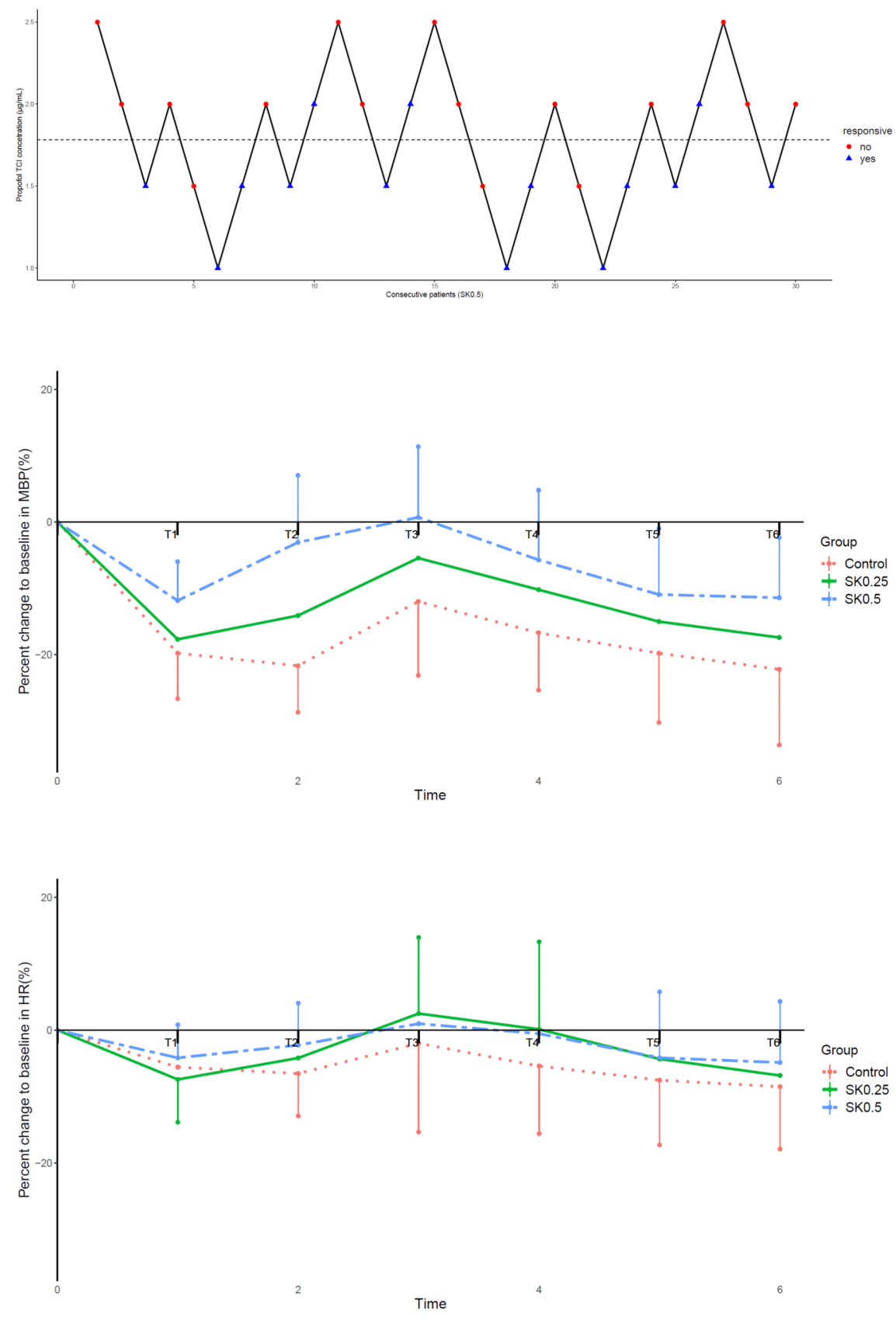